\title{
Free and Open Source Software in Costa Rican Local Governments
}

\author{
Francisco J. Mata, Ariella Quesada \\ Programa de Investigación y Extensión en Tecnología de Información y Desarrollo \\ Universidad Nacional de Costa Rica, Escuela de Informática \\ Heredia, Costa Rica \\ \{fmata, ariella.quesada.rosales\}@una.cr
}

\begin{abstract}
This paper presents and discusses the results from an electronic survey on the use of free and open source software (FOSS) by local governments in Costa Rica. Barriers preventing the use of this type of software are also identified. Comparison of the results from this survey with those obtained from a previous one, conducted under the same project, shows that Costa Rican local governments are increasingly using FOSS. Cost advantages provided by FOSS might be the main reason for this trend. However, other factors need to be considered for justifying the use of FOSS. These factors need to be articulated into organizational strategies -issue in which Costa Rican local governments are falling behind.
\end{abstract}

Keywords: Free and open software (FOSS), ICT use and adoption, local governments, Costa Rica

\section{Introduction}

With the aim of promoting the use of free and open source software (FOSS) in Costa Rica, the project "Strengthening ICT Capacities in Small and Medium Enterprises and Local Governments through the Use of FOSS" (more details about this project can be found in Mata et al. [1]) was initiated in 2009 by the Universidad Nacional de Costa Rica (UNA) with the United Nations Development Programme (UNDP) and the Ministry of Economy, Industry and Commerce (MEIC) of Costa Rica, and with funding from the Democratic Governance Thematic Trust Fund (DGTTF) - administered by UNDP. In 2012, a new component was added to this project regarding the use of FOSS in the national government in Costa Rica, which complemented the work previously conducted on local governments.

The above-mentioned project included as one of its objectives to assess the use of FOSS in Costa Rican local governments, as well as to identify barriers to its use, with the aim of proposing strategies that would allow local governments to take advantage of such type of software in benefit of citizens. It is for this reason that field research involving Costa Rican local governments was undertaken in 2012 through an electronic survey. This field survey follows a previous one conducted in 2009 under this same project, which allowed a longitudinal comparison of results.

This article is divided in five sections. The second section presents related work in this area. The methodology used is described in the third section. The fourth section discusses the main results obtained from the 2012 field survey and compares them with the previous survey. Conclusions and recommendations are presented in the last section.

This is an expanded version of the article "Usage and Limitations of Free and Open-Source Software in Costa Rican Local Governments," presented in the XXXIX Latin American Conference on Informatics (CLEI 2013). Information in this article was also presented in the section "Uso del software libre en los gobiernos locales" prepared by the authors and contained in the report "Retos y Oportundiades del Software Libre en la Administración Pública en Costa Rica," published by the United Nations Development Programme-Costa Rica (UNDP) and the Universidad Nacional de Costa Rica (UNA) [2]. 


\section{Related Work}

According to Hwang [3], five factors influence the adoption of FOSS in the public sector: i) cost reduction in software, ii) greater security and transparency, iii) interoperability, iv) technological independence, and v) economic development.

Regarding software cost, Hwang considers four components: acquisition cost, migration cost, management cost, and support cost. Although these line items can be reduced when FOSS is implemented, Hwang warns that cost-benefit for this type of software is not the same for every local government. Furthermore, he claims that FOSS implementation can foster collaboration with the local software industry and strengthen national competitiveness.

For Saroka and Poggi [4], the use of FOSS has to be promoted by local governments for two main reasons: i) to avoid restrictions related to legal requirements such as transparency and security, and ii) to support an efficient administration capable of promoting the exchange of software and the interoperability of systems. On the other hand, Ghosh et al. [5] indicate that the arguments in favor for adopting FOSS in the public sector can be summarized into i) lowering costs, ii) achieving technological independence, iii) obtaining software in an efficient manner, and iv) developing capacity to customize applications.

Therefore cost, security, transparency, technological independence and interoperability are recurrently cited in the literature as important factors for implementing FOSS in the public sector. These factors are complemented by additional advantages mentioned in some of the previous articles, such as obtaining an efficient administration and promoting collaboration with the local ICT industry.

On the other hand, Del Nagy et al. [6] describe five main barriers for adopting FOSS: learning barriers, integration with legacy systems, forking, sunk costs, and technological immaturity. Learning barriers are reflected by lack of awareness on FOSS availability or lack of technical knowledge needed to implement and use it. Problems regarding integration refer to difficulties experienced when FOSS is interconnected to legacy systems. Forking is related to the fact that FOSS applications are usually developed by different groups which may follow different architectures; therefore, in spite of using open standards FOSS applications might be also problematic to interoperate. Sunk costs, particularly reflected in previous investments in proprietary software (for example software acquisition and learning) are likely to dissuade organizations to migrate to FOSS. Finally, FOSS is often considered an immature technology. This is in great part supported by the belief that goods available for free have a lower quality than those for which it is necessary to pay, as it is the case with proprietary software. The fact that FOSS is developed by volunteers in their free time and without supervision or economic incentives reinforces this perception. These authors not only describe these barriers but also propose remedies to them. In this way, they address an important issue regarding FOSS: there are factors limiting the effective use of FOSS in organizations. This is often overlooked in the literature due to the enthusiastic point of view taken by most authors in favor of FOSS.

Del Nagy et al. [6] also provide useful data on the market share of FOSS applications (see Table 1). According to these authors, the most commonly used FOSS applications relate to web servers and e-mail clients, followed by server operating systems and database management systems (DBMS).

Table 1. Market Share for FOSS Applications

\begin{tabular}{c|c}
\hline Application & Market share estimates \\
\hline Web servers & $55-65 \%$ \\
\hline E-mail clients & $42-76 \%$ \\
\hline Server operating systems & $28-35 \%$ \\
\hline Database management systems & $29-33 \%$ \\
\hline Internet browsers & $10-27 \%$ \\
\hline Office applications & $2-4 \%$ \\
\hline Workstation operating systems & $1-3 \%$ \\
\hline Source: Adapted from Del Nagy et al. [6]
\end{tabular}

The literature on the use of FOSS in the public sector is relatively scarce. Alves and Pessoa [7] describe the use of FOSS in the public sector in Brazil. This country has created an ecosystem for using FOSS in public organizations, including local governments. This ecosystem has been instrumental for implementing the Brazilian Public Software Portal, ${ }^{1}$ and devising the concept of Public Software. Public software, although based on the basic concept of FOSS, differs from it on legal terms (licensing).

Valimaki et al. [8] studied the use of FOSS in Finish local governments. They found that Internet services at the server side are the most common FOSS applications used. These are followed by application servers, database software, and Internet services at the client side. On the other hand, accounting software is the category

\footnotetext{
${ }^{1}$ http://www.softwarepublico.gov.br.
} 
where FOSS is used the least. The most important factors found for using FOSS in the Finish local governments are price, total cost of ownership, security and "easy license management." In contrast, code availability and the possibility to make changes are the least important factors.

There are few related studies on the use of FOSS in public administration in Latin America. Only two such studies were identified in this region: one conducted by Sax [9] for Chile, and another by the Asociación Mexicana Empresarial de Software Libre (AMESOL) [10] for Mexico.

Sax [9] conducted in 2004 a survey considering ICT decision makers in the public sector in Chile. According to this survey, $48 \%$ of the respondents indicated having used FOSS and $11 \%$ expressed intentions to use. A notable result in this study is that the percentage of usage of FOSS diminishes in rural areas.

Public organizations in Chile primarily use FOSS in e-mail, web and security servers (94\%), followed by DBMS (61\%). On the other hand, FOSS is less likely used for office applications (42\%). Regarding their experience in implementing FOSS, 77\% of the organizations surveyed indicated to have between 2 to 5 years, with an average of 3.3 years. Thirty-seven percent of the respondents indicated that security is the most important reason for implementing FOSS.

Regarding the effect of FOSS, most of the Chilean respondents experienced a positive economic impact derived from smaller costs in implementation, maintenance and payment of software licenses, and also from greater stability in the applications. In relation to licensing, this study indicates that savings in this line allowed the creation of new job positions, and also the opportunity to reinvest these savings in training, consulting or equipment.

In 2009, AMESOL [10] conducted an opinion survey in Mexico with the aim of obtaining the perceptions of public servants regarding the use of FOSS. To obtain the data, both an electronic and a telephone survey were used. Forty-one percent of the persons surveyed indicated having used FOSS in their organizations. Also 48\% of them pointed out that there was no guidelines or policies regarding the use of FOSS in their organizations.

The main FOSS applications used in workstations corresponded to operating systems, office applications, and Internet browsers. On the other hand, operating systems, web servers, DBMS, and web development software were the main FOSS applications used in servers.

Respondents, in general, expressed satisfaction with FOSS applications. Furthermore, they indicated good results considering the implementation of FOSS in the organization, particularly in matters related to achieving lower costs - reflected mainly in licensing and in the adaptation of existing software. This adaptation satisfied the needs of the organization and resulted in easy-to-use software. Nevertheless, the persons surveyed recognized training as an important factor affecting the use of FOSS. Finally the study found end-user training, effective change management, institutional support, previous experience using FOSS, and having professional support services as critical success factors for implementing FOSS.

In summary, the respondents surveyed in Mexico assessed as good their experience regarding the use, operation and maintenance of FOSS. This was evidenced in its performance, the existence of tools easy to install and use, the availability on Internet of technical support and information, and the need for less maintenance for this type of software.

Finally and as already mentioned, a survey about the use of FOSS in Costa Rican local governments was conducted in 2009, as part of the project "Strengthening ICT Capacities in Small and Medium Enterprises and Local Governments through the Use of FOSS." Twenty-nine responses out of the 81 local governments were received, accounting to $36 \%$ participation in the survey for these organizations. Results from this survey have not been published, yet can be summarized as follows:

- Forty-three percent of the respondents indicated that their organizations used FOSS or were in the process of implementing it.

- In general, organizations were satisfied with the implementation and use of FOSS.

- Cost and stability were the main factors for using FOSS.

- Operating systems, DBMS, and content management systems (CMS) were the major FOSS applications reported.

- Training was identified as a major cost factor by the respondents for implementing FOSS.

- The lack of institutional guidelines or policies was reported as the major barrier for implementing FOSS.

- The following factors were identified as important for implementing FOSS: ICT staff training and availability of human resources.

- Resistance to change was identified as the main reason for not using FOSS, in the case of local governments reporting not having yet installed this type of software. 


\section{Methodology}

This study is based on an electronic survey, as previously indicated. For this purpose, we used the FOSS application LimeSurvey. ${ }^{2}$

\subsection{Questionnaire}

The questionnaire used in the first survey conducted in 2009, previously described, was used as a starting point for developing a new questionnaire. This was complemented with the studies presented in the previous section, particularly the one from Sax [9] and AMESOL [10]. The questionnaire was organized in four sections: i) knowledge and implementation of FOSS, ii) technological infrastructure and use of FOSS, iii) perceptions and opinions about FOSS, and iv) reasons for not using FOSS.

\subsection{Population and Sample}

Similar to the previous study, the unit for this study was Costa Rican local governments -better known in the country as municipalities. They are the political representation of each county in the country. There are currently 81 such entities. Due to the size of the population, a census was conducted for this study.

The survey was addressed to the person in charge of the ICT department in the local government, in case such department existed in the organization; otherwise, it was sent to the person in charge of the information systems (IS) functions. Based on the experience with the previous survey, the list of local governments was first analyzed to determine whether an ICT department existed or otherwise an IS function could be identified in the local governments. This analysis allowed to identify that only 71 local governments had an ICT department in their organizational structure or at least had a person in charge of the IS functions. The survey was applied during a 30-day period, between February and March 2012. Electronic reminders and follow-up telephone calls were used as mechanisms to increase the response rate. As Table 2 shows, 35 questionnaires were completed, more than in the previous survey. Furthermore, this number corresponded to a response rate of nearly $50 \%$, correcting the population size as previously explained. This response rate can be considered good for an online survey [11].

Table 2. Population, Sample and Response Rate

\begin{tabular}{|c|c|}
\hline & \\
\hline Total number of questionnaires & 71 \\
\hline Questionnaires completed & 35 \\
\hline Response rate & $49 \%$ \\
\hline
\end{tabular}

\section{Results}

Before presenting the results obtained from the survey, it is important to take into consideration that although the local governments that participated in the survey have on average 130 employees, ${ }^{3}$ the staff in the ICT departments or dedicated to the IS function is very small (mainly one or two persons ${ }^{4}$ ). Furthermore, since the questionnaire used in the 2012 survey is an improved version of the one used in the 2009 survey - the most recent has more questions than the previous-, not all questions can be compared between the two surveys.

\subsection{Knowledge and Implementation of FOSS}

As shown in Table 3, 69\% of local governments participating in the 2012 survey indicated to have implemented or being in the process of implementing FOSS, $14 \%$ use only proprietary software and 17\% did not provide an answer.

A comparison between the 2009 and the 2012 surveys shows an increase in the use of FOSS and a reduction on the reliance of using exclusively proprietary software in local governments (see also Table 3 ).

\footnotetext{
2 See http://www.limesurvey.org for more information.

${ }^{3}$ The mode of this value is 30 workers.

${ }^{4}$ The average of employees in the ICT department or IS function is 2 and the mode 1.
} 
Table 3. Comparison on the Use of FOSS in Local Governments between 2009 and 2012

\begin{tabular}{l|c|c}
\hline & $\mathbf{2 0 0 9}$ & $\mathbf{2 0 1 2}$ \\
\hline Have implemented or are in the process of implementing FOSS & $55 \%$ & $69 \%$ \\
\hline Use only proprietary software & $36 \%$ & $14 \%$ \\
\hline No response & $9 \%$ & $17 \%$ \\
\hline
\end{tabular}

Source: Own elaboration using data from the survey "Use and Barriers of FOSS in Costa Rican Local Governments," UNA-UNDP, February-March 2012 and "Use of FOSS in Costa Rican Governments," UNA-UNDP-MEIC, November-December 2009.

It is interesting to note that FOSS implementation in local governments started very timidly in the year 2002, stopped until 2005; yet continued again in 2006 taking impetus between 2010 and 2011, as shown in Figure 1.

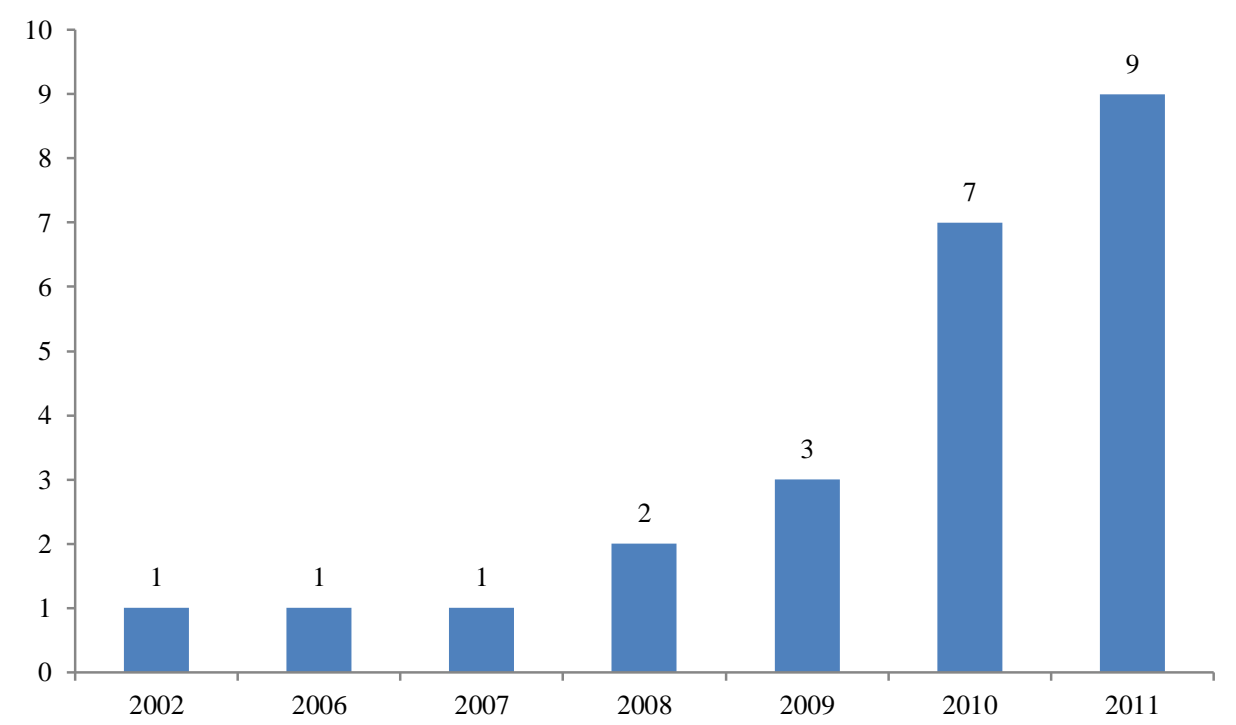

Source: Own elaboration using data from the survey "Use and Barriers of FOSS in Costa Rican Local Governments," UNA-UNDP, February-March 2012.

Figure 1. Year in which FOSS Implementation Began in the Local Governments 2012 Survey

Related to the previous, $79 \%$ of the local governments that have implemented or are in the process of implementing FOSS in 2012 gave a high level of importance to this type of software. Nevertheless, 75\% responded that there is no guideline or policy in the organization regarding the use of FOSS — higher than what has been reported in the case of Mexico [10]. Therefore, it can be inferred that FOSS implementation in Costa Rican local governments is the result of the interest of ICT staff in the organization and not of organizational strategies (see [1] for more details). In spite of this situation, an improvement regarding the existence of organizational guidelines and/or policies for FOSS in the case of Costa Rican local governments can be observed (see Table 4), when the results are compared to those obtained in 2009. As indicated before, the lack of institutional guidelines or policies was identified in the 2009 survey as the major barrier for implementing FOSS in the local governments.

Table 4. Existence of Guidelines or Policies for Using FOSS in Costa Rican Local Governments 2009 versus 2012

\begin{tabular}{l|c|c}
\hline & $\mathbf{2 0 0 9}$ & $\mathbf{2 0 1 2}$ \\
\hline Existence of guidelines of policies regading FOSS & $7 \%$ & $25 \%$ \\
\hline \multicolumn{2}{l}{ Source: Own elaboration using data from the survey "Use and Barriers of FOSS in Costa } \\
Rican Local Governments," UNA-UNDP, February-March 2012 and "Use of FOSS in Costa \\
Rican Governments," UNA-UNDP-MEIC, November-December 2009.
\end{tabular}

\subsection{Technological Infrastructure and Use of FOSS}

The number of computers available in the local governments surveyed in 2012 ranged from 6 to 190, with an average of 70. Servers, on the other hand, fluctuated between 1 and 11, with an average of 5 .

Figure 2 shows the different categories of applications and the type of software used for them (FOSS, proprietary, or both) in 2012. As depicted in this figure, the local governments used FOSS primarily for programming websites and for website and e-mail servers. Internet browsers, server operating systems, and office applications are among the software categories in which both FOSS and proprietary software are used. Proprietary software, on the other hand, is used for the remaining categories. A notable example is workstation 
operating systems. However, little utilization is observed for customer relationship management (CRM), document management, software development, management applications, and collaborative tools. These results show some consistency to those presented by Del Nagy et. al [6], Valimaki et al. [8], and Sax [9].

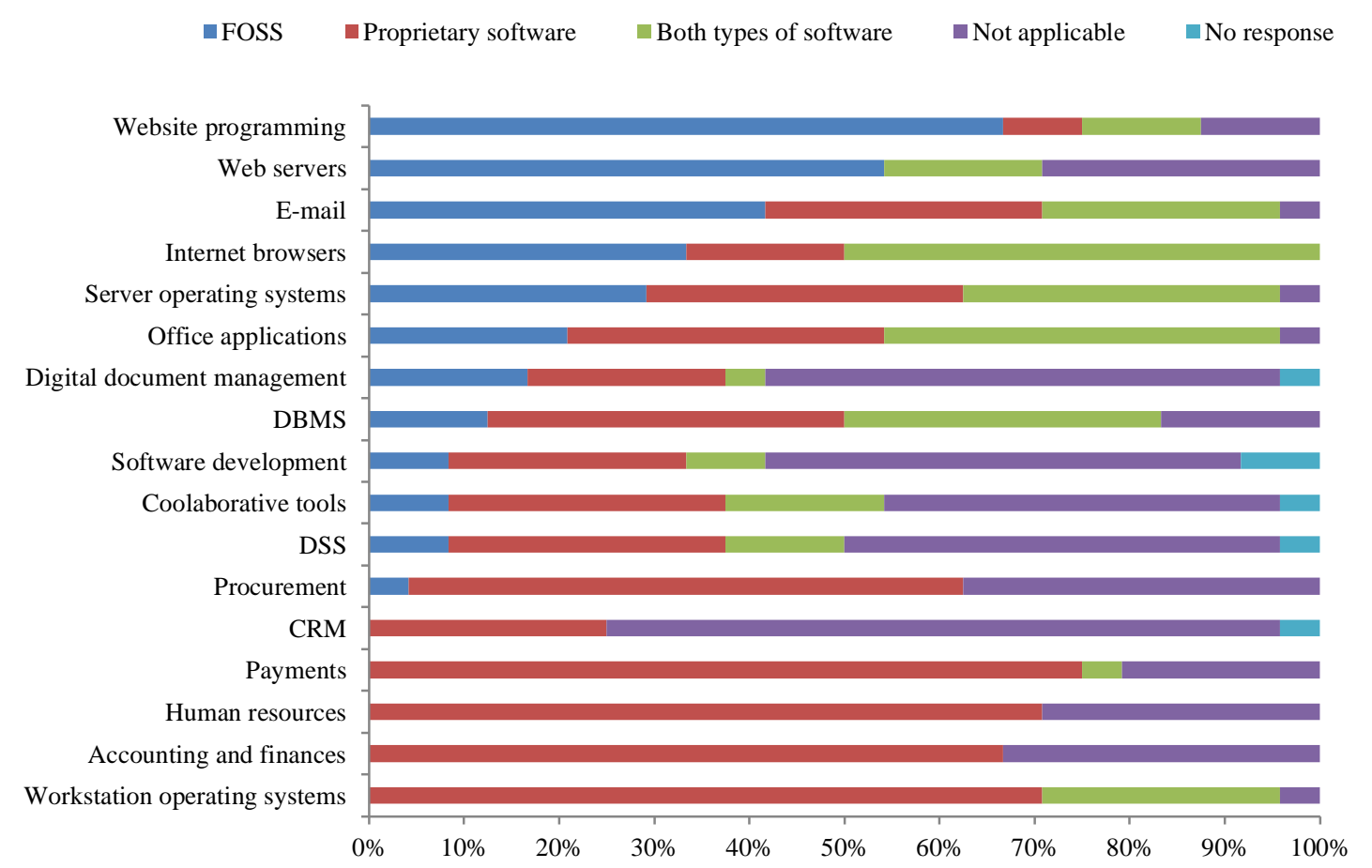

Source: Own elaboration using data from the survey "Use and Barriers of FOSS in Costa Rican Local Governments," UNA-UNDP, February-March 2012.

Figure 2. Type of Software Used in the Local Governments in 2012, by category of applications

As previously indicated in the 2009 survey, operating systems, DBMS, and CMS were found as the major FOSS applications used by local governments. However, the use of a more refined list of categories in 2012 makes it difficult to compare the results obtained for different types of software between both surveys.

\subsection{Perceptions and Opinions about FOSS}

Figure 3 shows that the local governments participating in the 2012 survey considered their experience as good related to the use, maintenance, installation and compatibility of FOSS. Only training presented an evaluation of regular.

Table 5 presents the relevant factors enabling FOSS implementation. Human resource factors topped this list: $67 \%$ of the respondents pointed out the commitment of the staff assigned to the implementation process, followed by $62 \%$ stressing the importance of training for ICT staff. Fifty-eight percent indicated financial limitations and organizational support as enabling factors for implementing FOSS. Lastly, 54\% identified collaboration from universities and other organizations as another relevant factor for promoting FOSS.

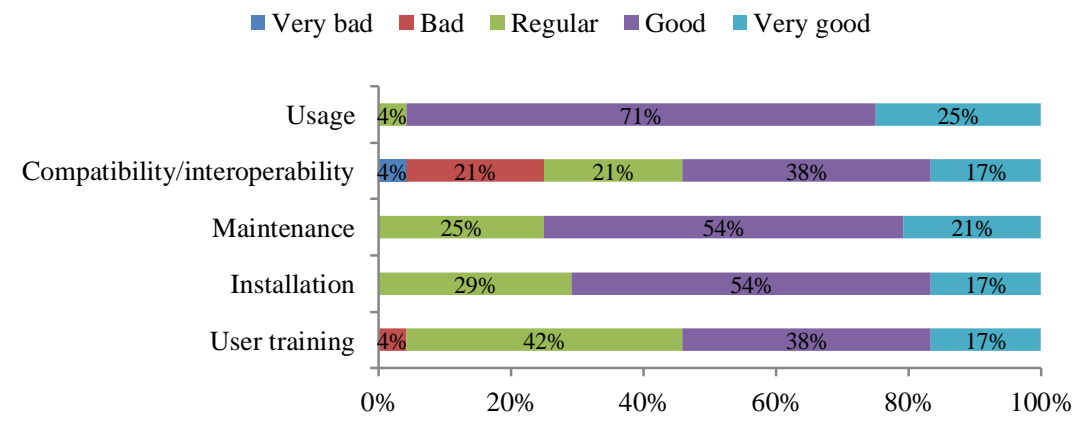

Source: Own elaboration using data from the survey "Use and Barriers of FOSS in Costa Rican Local Governments," UNA-UNDP, February-March 2012.

Figure 3. Experience with FOSS in 2012 
Table 5. Relevant Factors Enabling FOSS Implementation in the Local Governments in 2012

\begin{tabular}{lc}
\hline \multicolumn{1}{c}{ Factor } & Response \\
\hline Commitment of the staff assigned to the implementation process & $67 \%$ \\
\hline Training for ICT staff & $62 \%$ \\
\hline Financial limitations & $58 \%$ \\
\hline Organizational support & $58 \%$ \\
\hline Collaboration from universities and other organizations that promote FOSS & $54 \%$ \\
\hline Source: Own elaboration using data from the survey "Use and Barriers of FOSS in Costa Rican Local \\
Governments," UNA-UNDP, February-March 2012 and "Use of FOSS in Costa Rican Governments," \\
\hline UNA-UNDP-MEIC, November-December 2009.
\end{tabular}

Furthermore, securing organizational support for implemented FOSS required the greatest effort $-42 \%$ of the respondents stated that obtaining this support required much effort, above the other factors considered (see Figure 4). This condition was identified previously as an enabling factor. Other categories considered such as training, staff availability, installation, equipment acquisition required mostly a regular effort, as shown in the same figure.

Regarding cost factors, $42 \%$ of the respondents to the 2012 survey considered that FOSS had a lesser cost for training, equipment, and technical support than proprietary software (see Table 5). However, a greater proportion of participants considered both types of software alike regarding installation costs.

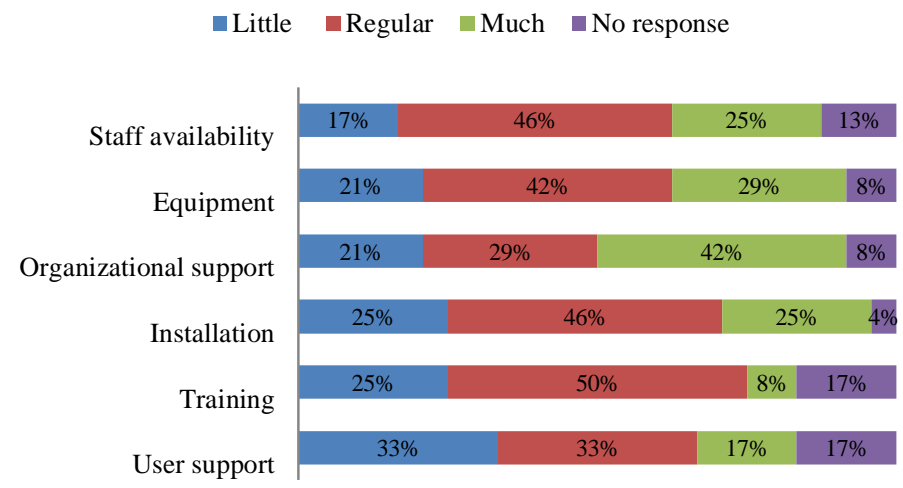

Source: Own elaboration using data from the survey "Use and Barriers of FOSS in Costa Rican Local Governments," UNA-UNDP, February-March 2012.

Figure 4. Level of Effort Required to Implement FOSS in the Local Governments in 2012

As Table 6 also shows, changes in the opinions between FOSS and proprietary software for the cost factors can be observed between 2009 and 2012. Respondents to the 2009 survey tended to favor more an opinion of a lesser cost factor for equipment, installation, and technical support for FOSS than proprietary software, in comparison to the 2012 survey. On the other hand, training cost is considered equal for both types of software in 2009, yet less for FOSS than proprietary software in 2012.

Table 6. Opinions about Cost Factors for FOSS compared to Proprietary Software

\begin{tabular}{|c|c|c|c|c|c|c|c|c|}
\hline \multirow{2}{*}{ Cost factor } & \multicolumn{4}{|c|}{2009} & \multicolumn{4}{|c|}{2012} \\
\hline & Less & Equal & Greater & NR & Less & Equal & Greater & NR \\
\hline Equipment & $67 \%$ & $25 \%$ & $0 \%$ & $8 \%$ & $42 \%$ & $29 \%$ & $13 \%$ & $17 \%$ \\
\hline Installation & $58 \%$ & $8 \%$ & $25 \%$ & $8 \%$ & $29 \%$ & $33 \%$ & $17 \%$ & $21 \%$ \\
\hline Training & $33 \%$ & $50 \%$ & $8 \%$ & $8 \%$ & $42 \%$ & $25 \%$ & $8 \%$ & $25 \%$ \\
\hline $\begin{array}{l}\text { Technical } \\
\text { support }\end{array}$ & $58 \%$ & $33 \%$ & $0 \%$ & $9 \%$ & $42 \%$ & $38 \%$ & $0 \%$ & $21 \%$ \\
\hline
\end{tabular}

The technical factors influencing the decision to use FOSS in the local governments are presented in Figure 5. Within these factors excel technological independence; virus absence; stability; customization; quality and variety of applications; cost for software update; and cost for installation, integration and customization. 


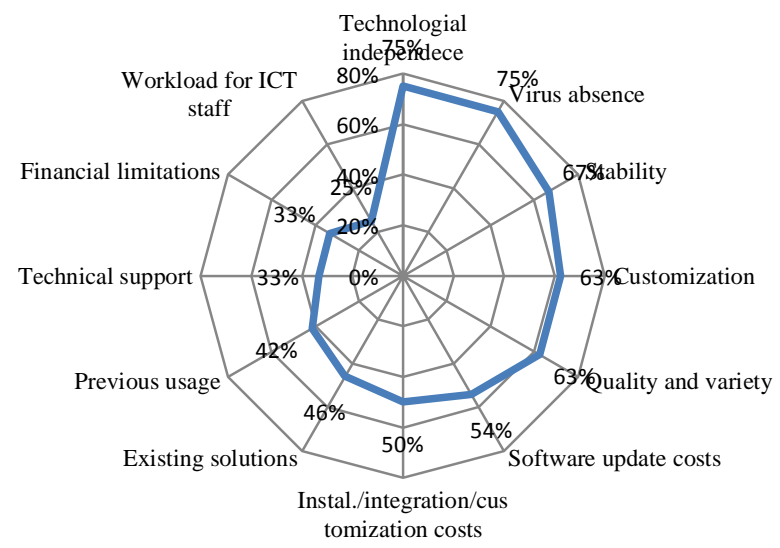

Source: Own elaboration using data from the survey "Use and Barriers of FOSS in Costa Rican Local Governments," UNA-UNDP,

February-March 2012.

Figure 5. Technical Factors Influencing the Decision to Use FOSS in Local Governments in 2012

\subsection{Reasons for Not Using FOSS}

The local governments that participated in the 2012 survey but have not implemented FOSS (32\%) identified barriers related to human resources as the main limitations for using this type of software in their organizations. In this regard, more than one-third of these local governments mentioned i) time limitations of the ICT staff for planning and executing software migration, and ii) resistance to change by users in the organization. In second place, more than a quarter of such governments recognized the absence of policies, security concerns, doubts about the real cost of the change, difficulties for integrating existing applications with FOSS applications, and existing priorities - which makes it difficult to implement new projects relying on FOSS - as other barriers (see Table 7).

Table 7. Reasons for Not Using FOSS in the Local Governments in 2012

\begin{tabular}{lc}
\hline \multicolumn{1}{c}{ Factor } & Response \\
\hline Limitations of the ICT staff for planning and executing change proposals & $36 \%$ \\
\hline Resistance to change by users in the organization & $36 \%$ \\
\hline Absence of policies & $27 \%$ \\
\hline Security concerns & $27 \%$ \\
\hline Doubts about the real cost of the change & $27 \%$ \\
\hline Difficulties for integrating existing applications with FOSS applications & $27 \%$ \\
\hline Other priorities in IT & $27 \%$ \\
\hline Source: Own elaboration using data from the survey "Use and Barriers of FOSS in Costa Rican Local \\
\hline Governments," UNA-UNDP, February-March 2012.
\end{tabular}

Similarly to the results of the 2012 survey, resistance to change was also identified as one of the main reasons for not using FOSS in 2009.

Lastly, local governments that have not implemented FOSS mentioned to be interested mainly in using FOSS for operating systems (45\%) and telecommunication applications (36\%) (see Table 8). 
Table 8. FOSS Applications of Interest by Local Governments that Have Not Implemented FOSS in 2012

\begin{tabular}{lc}
\hline \multicolumn{1}{c}{ Application } & Response \\
\hline Operating systems & $45 \%$ \\
\hline Telecommunication applications & $36 \%$ \\
\hline Office applications & $27 \%$ \\
\hline DBMS & $27 \%$ \\
\hline CMS & $27 \%$ \\
\hline Collaborative tools & $18 \%$ \\
\hline Decision support systems (DSS) & $9 \%$ \\
\hline CRM & $9 \%$ \\
\hline
\end{tabular}

Source: Own elaboration using data from the survey "Use and Barriers of FOSS in Costa Rican Local Governments," UNA-UNDP, February-March 2012.

\section{Conclusions and Recommendations}

In general, the Costa Rican local governments participating in this study valued worthy their experience with FOSS and showed a significant use of this type of software. Sixty-eight percent of the respondents indicated having used or been in the process of implementing FOSS. This type of software is mainly used for web programming and for web and e-mail servers.

Although FOSS implementation began in the Costa Rican local governments in 2002, in a very incipient manner, it stopped for three years reinitiating again in 2006 in an embryonic mode. Nevertheless, it continued steadily taking momentum between 2010 and 2011. It is interesting to note that this process can be attributed mainly to the interest of the ICT staff of the local governments in using FOSS rather to the existence of organizational guidelines or policies. Although, $25 \%$ of the respondents indicated that currently they have such guidelines or policies — which is an improvement to the $7 \%$ of the local governments previously identified in the 2009 survey - , most of the local governments participating in the study lack organizational strategies for using FOSS.

Furthermore, cost advantages of FOSS over proprietary software - in conjunction with budgetary constraints in public organizations - seem to be a driving force for the increase in use of this type of software in Costa Rican public organizations [12]. In fact, financial limitations were identified in this study as a factor enabling FOSS in Costa Rican local governments. For this reason, it is important for these organizations to develop strategies for using FOSS in such a way that strategic considerations, and not just cost concerns, are used to justify this type of software. These strategies have to build on factors enabling FOSS implementation, such as the commitment of the staff assigned to the implementation process and training for this staff, and also on technical factors such as technological independence, virus absence, stability, customization, and quality and variety of applications. Several of these technical factors are consistent with the ones commonly cited in the literature, as explained in section 2.

Furthermore, organizational strategies for using FOSS should consider limiting factors identified in this study, for example, time limitations of the ICT staff and resistance to change by users in the organizations. Interestingly, these barriers do not coincide with those presented by Nagy et al. [6] and discussed in section 2.

Also, the principles of the Open Government Partnership should be included within such guidelines and policies, as proposed by Mata and Aguilar [12]. This partnership, to which Costa Rica is a member since 2012, has as guiding principles: i) increasing the availability of information about governmental activities, ii) supporting civil participation, iii) implementing the highest standards of professional integrity throughout the administrations, and iv) increasing access to new technologies for openness and accountability [13]. These objectives are very much in line with the philosophy behind FOSS.

The development of clear strategies could avoid the Costa Rican local governments to fall into the trap of justifying FOSS simply on licensing costs. Although, cost considerations are revealed important in this study, migration to FOSS entails training costs and risks [12]. Training should not only be provided to end-users but also to technical staff. As Del Nagy et al [6] argue, many times organizations do not use FOSS simply because they do not know about the existence of comparable FOSS applications. For this reason, Aguilar [14] identified a series of potential FOSS applications for Costa Rican public organizations. In addition, collaboration with universities — deemed important for the local governments surveyed — can also be useful for providing training. On the other hand, risks can be reduced by using methodologies to guide software migration processes [12] (see for example [15]).

Finally, the development of organizational strategies for using FOSS have the additional advantage of securing organizational support, which was identified in this study as the factor requiring more effort for implementing FOSS and also as an enabling factor for such implementation. 


\section{References}

[1] F.J. Mata, I. Hernández and C. Flores, "Fortalecimiento de la capacidades TIC en pymes y gobiernos locales mediante el uso de software libre", XXXVII Conferencia Latinoamericana en Informática (CLEI 2011), Quito, Ecuador, October 2011.

[2] F.J. Mata, C. Flores, R. Zambrano and G. Pacheco (eds.), Retos y Oportunidades del Software Libre en la Administración Pública en Costa Rica, San José, Costa Rica: Programa de las Naciones Unidas para el Desarrollo (PNUD) and Universidad Nacional de Costa Rica (UNA), 2013. Available: https://www.undpegov.org/sites/undpegov.org/files/SoftwareLibre Administracion Publica CR $\underline{0 . p d f}$

[3] S.Y. Hwang, "Adopting open source and open standards in the public sector: five deciding factors behind the movement", Michigan Journal of Public Affairs, vol. 2, 2005.

[4] R. Saroka and E. Poggi, "Software de código abierto en la administración pública". In S. Finquelievich (Ed.), E-Política y e-Gobierno en América Latina, Buenos Aires, Argentina, pp 183-199, 2005.

[5] R.A. Ghosh, B. Krieger, R. Glott, and G. Robles, Open Source Software in the Public Sector: Policy within the European Union. International Institute of Infonomics, University of Maastricht, The Netherlands, 2002.

[6] D. Del Nagy, A. Yassin and A. Bhattacherjee, "Organizational adoption of open source software: barriers and remedies". Communications of the ACM, vol. 53, no.3, pp. 148-151, 2010.

[7] A.M. Alves and M. Pessoa, "Brazilian public software: beyond sharing" in Proc. ACM International Conference on Management of Emergent Digital EcoSystems (MEDES'10), Bangkok, Thailand, 2010, pp. 73-80.

[8] M. Valimaki, V. Oksanen and J. Laine, "An empirical look at the problems of open source adoption in finnish municipalities" in Proc. ACM of the 7th International Conference on Electronic Commerce (ICEC '05), Xian, China, vol. 113, pp. 514-520, 2005.

[9] M. Sax, Economic Efficiency of Free and Open Source Software in the Public Sector: The Example of Chile. Santiago, Chile: United Nations, 2006.

[10] AMESOL, Percepción del Uso de Software Libre en el Sector Público en México, Asociación Mexicana Empresarial de Software Libre, A. C., 2009

[11] D.D. Nulty, “The adequacy of response rates to online and paper surveys: what can be done?". Assessment \& Evaluation in Higher Education, vol.33, no.3, pp. 301-314, 2008

[12] F.J. Mata, and M. Aguilar, Recomendaciones y Conclusiones, in F.J. Mata, C. Flores, R. Zambrano and G. Pacheco (eds.), Retos y Oportunidades del Software Libre en la Administración Pública en Costa Rica, San José, Costa Rica: Programa de las Naciones Unidas para el Desarrollo (PNUD) and Universidad Nacional de Costa Rica (UNA), pp. 101-108, 2013. Available: https://www.undpegov.org/Software-LibreCosta-Rica

[13] Open Government Partnership. Open Government Declaration. September, 2011. Available: http://www.opengovpartnership.org/about/open-government-declaration

[14] M. Aguilar, Oportunidades para el Uso del Software Libre en la Administración Pública en Costa Rica, in F.J. Mata, C. Flores, R. Zambrano and G. Pacheco (eds.), Retos y Oportunidades del Software Libre en la Administración Pública en Costa Rica, San José, Costa Rica: Programa de las Naciones Unidas para el Desarrollo (PNUD) and Universidad Nacional de Costa Rica (UNA), pp. 89-100, 2013. Available: https://www.undpegov.org/Software-Libre-Costa-Rica

[15] Centro Nacional de Referencia de Aplicación de las TIC Basadas en Fuentes Abiertas (CENATIC). Modelo Metodológico. Available: http://wiki.cenatic.es/wikiesp/index.php/Modelo_Metodol\%C3\%B3gico 